\title{
FORMAÇÃO DE EXTENSIONISTAS: CONSTRUÇÃO COLETIVA DE PROJETO DE CURSO COM BASE NA INOVAÇÃO SOCIAL
}

\author{
EDUCATION OF OUTREACH UNDERGRADUATE \\ STUDENTS: COLLECTIVE CONSTRUCTION OF A COURSE \\ PROJECT BASED ON SOCIAL INNOVATION
}

Douglas Paulesky Juliani*

\section{RESUMO:}

Este artigo relata o processo de construção do projeto pedagógico de um curso voltado à formacão de extensionistas. Tal projeto originou-se da necessidade de qualificar as atividades de extensão na Rede Federal de Educação; contribuir para a curricularização da extensão; promover o aprofundamento teórico da comunidade acadêmica nesta temática e capacitar os coordenadores de extensão. Para a elaboração do produto educacional proposto, desenvolveu-se uma pesquisa aplicada, de abordagem qualitativa, cujos procedimentos de coleta de dados envolveram pesquisa bibliográfica, documental, grupos focais (cocriações) e técnicas do Design Thinking. Como resultado, concebeu-se uma proposta de curso que visa contribuir para enriquecer a construção de conhecimentos relacionados à extensão, permitindo ao discente participante a execução de ações de extensão mais qualificadas e integradas ao ensino e à pesquisa.

Palavras-chave: Extensão; Inovação Social; Cocriação; Institutos Federais.

\begin{abstract}
:
This article reports the construction of the pedagogical project of a course focused on outreach practice. The project emerged from the need to qualify outreach activities in the Federal Education Network, to contribute to the insertion of outreach activities in the curriculum of the courses, to deepen the theoretical knowledge of the academic community about the theme and to form outreach coordinators. For the elaboration of the educational product, an applied qualitative research was developed, whose data collection involved bibliographical, documentary, focus groups (co-creations) and Design Thinking techniques. As a result, a course proposal was conceived that aims to enrich the construction of knowledge related to outreach activities, allowing the participating undergraduate students to carry out more qualified outreach actions integrated to teaching and research.
\end{abstract}

Keywords: Outreach activities; Social Innovation; Co-creation; Federal Institutes. 


\section{Introdução}

Os espaços nacionais de discussão e estudo acerca da extensão, como congressos, revistas e fóruns, têm revelado um cenário ainda incipiente no que se refere à consolidação do arcabouço teórico da extensão. Nos institutos federais, onde a temática se formalizou apenas em 2008, por meio de Decreto-lei, essa necessidade de desenvolvimento e disseminação de conhecimentos apresenta-se ainda mais evidente de ser explorada cientificamente.

As análises dos dados coletados desde 2015 pela equipe da Diretoria de Extensão do Instituto Federal de Santa Catarina (IFSC), por meio das estatísticas das atividades desenvolvidas e do contato constante com a realidade vivenciada nos seus 22 campi, configuram um cenário que enfatiza a necessidade de um aprofundamento teórico por parte da comunidade acadêmica acerca da extensão.

Outra demanda nacional está formalizada no Plano Nacional de Educação, o qual exige, no mínimo, $10 \%$ do total de créditos curriculares da graduação em programas e projetos de extensão universitária, orientando sua ação, prioritariamente, para as áreas de grande pertinência social (BRASIL, 2018).

A Diretoria de Extensão do IFSC aponta mais um desafio - a alta rotatividade dos Coordenadores de Extensão, função presente em todos os seus campi. Segundo a diretoria, essa equipe muda a cada ano, acarretando a necessidade de capacitação regular desse público estratégico que não tem disponível uma formação direcionada para assumir tal função.

De acordo com os fatos supracitados, o estado da arte difuso da extensão, a fragilidade do entendimento da extensão por parte da comunidade acadêmica, a demanda legal estabelecida no Plano Nacional de Educação (PNE) e a alta rotatividade dos coordenadores de extensão nos campi acentuam a urgência da formulação de estratégias para capacitar a rede federal de educação, com o intuito de contribuir para o desenvolvimento de ações educativas significativas para os alunos e de forte impacto na comunidade.

Pesquisas realizadas em nível nacional pela equipe docente do Centro de Referência em Formação e Educação a Distância do IFSC (Cerfead) não identificaram capacitações com o propósito de qualificar especificamente para as atividades de extensão. Portanto, considerando os aspectos expostos, propôs-se a concepção de uma formação cujo objetivo seria potencializar o impacto dos institutos federais e universidades na sociedade e na formação do aluno, estimulando a integração das atividades de extensão com a pesquisa e o ensino. Neste cenário, este artigo tem como objetivo apresentar o processo de construção do projeto pedagógico da formação proposta.

\section{Metodologia}

Este trabalho relata o desenvolvimento de uma pesquisa aplicada, que intencionou resolver um problema real por meio da elaboração de um produto (um Projeto Pedagógico de Curso - PPC) no contexto educacional. Tem abordagem qualitativa, pois foi realizada por meio de pesquisa bibliográfica, documental (dados coletados nos arquivos da diretoria de extensão do IFSC) e grupos focais (cocriações). Não obstante, trata-se de uma pesquisa participante, já que um dos pesquisadores desenvolvedor do produto citado e autor deste artigo encontra-se lotado na referida diretoria (Cerfead) há cinco anos e atuou diretamente na coleta de dados documentais e na mediação dos grupos focais.

Para alcançar o objetivo de elaborar um projeto pedagógico de curso para a formação de extensionistas, os procedimentos foram desenvolvidos de forma coletiva e multidisciplinar. O Design Thinking foi usado de modo complementar a metodologias tradicionais de pesquisa para desenhar o projeto formativo, principalmente no planejamento e operacionalização das cocriações por meio dos grupos focais.

O Design Thinking é uma metodologia centrada no ser humano, isto é, que o considera como centro do desenvolvimento do projeto e possibilita sua participação ativa desde a identificação do problema até a avaliação das possíveis soluções. Isso porque o Design Thinking entende que as pessoas que convivem diariamente com um problema têm muito a contribuir para solucioná-lo. Portanto, aliando um bom conhecimento sobre o contexto com as habilidades criativas, é possível construir ideias de soluções que tenham significado emocional e funcional para as pessoas envolvidas no problema (IDEO, 2018).

$\mathrm{O}$ termo Design Thinking (DT) faz referência à maneira do designer de pensar - através do pensamento abdutivo, que busca formular perguntas para serem respondidas a partir das informações coletadas durante a observação. O DT também prioriza o trabalho colaborativo entre equipes multidisciplinares, que contribuem com diferentes perspectivas e ângulos em busca de soluções inovadoras (VIANNA et al., 2011). Esta metodologia pode ser considerada um modo de pensar, uma cultura, um olhar, um processo ou um método prático-criativo focado no ser humano, que busca inicialmente conhecer o contexto e observar as pessoas, para então identificar problemas e propor soluções inovadoras que se encaixem nele.

Com base nos princípios do Design Thinking, foram adotadas para a elaboração do PPC técnicas típicas desta metodologia, como o uso de "Cartões de Insight", que consiste em transformar os insights da pesquisa em cartões de rápida leitura e fácil manuseio; de "Critérios Norteadores", em que as diretrizes do projeto são constantemente evidenciadas para que não perca de vista ao longo de todas as etapas de desenvolvimento de soluções; de "Brainstorming" e de "Workshop de Criação", técnicas nas quais uma série de atividade é proposta de modo a estimular a criatividade, a colaboração e a geração de uma grande quantidade de ideias e de soluções inovadoras (BLEICHER, 2015). As referidas técnicas foram exploradas no processo de elaboração do PPC nos eventos de cocriação por meio de grupos focais.

O processo de construção do curso perpassou uma série de etapas, iniciando no levantamento das demandas formativas relacionadas à extensão, seguido da realização de grupos focais para aprofundar nas reflexões e em busca de ideias. Como público integrante desses grupos, que muito colaboraram para a construção do PPC relatado neste artigo, participaram membros da diretoria 
de extensão do IFSC (reitoria), coordenadores de extensão dos campi, professores internos e de instituições parceiras que possuem experiência em extensão.

Os dados coletados foram analisados, sistematizados e usados para a redação do PPC. Passou por análise da equipe da Diretoria de Extensão do IFSC, que ofereceu sugestões de melhoria. Incorporadas tais sugestões, o PPC foi então apreciado e aprovado pelo Colegiado de Ensino, Pesquisa e Extensão do IFSC (CEPE). Por fim, com a aprovação do CEPE, foi possível realizar a produção do material didático para oferta do curso na modalidade EaD. As etapas supracitadas podem ser visualizadas na Figura 1.

Destaca-se que a modalidade a distância foi escolhida considerando-se a realidade institucional apresentada: havia a necessidade de propor uma formação que fosse contínua e que atingisse gestores, servidores e coordenadores de extensão espalhados nos diferentes campi. Adicionalmente, depois de realizada a primeira oferta, compunha as estratégias de planejamento ampliar o público estratégico para servidores e alunos de toda a rede federal de educação e universidades. Para além disso, a flexibilidade e a autonomia da modalidade possibilitaram que todos os participantes pudessem estudar no seu ritmo e conforme sua disponibilidade de tempo.

Figura 1 - Etapas da construção do curso de extensão.
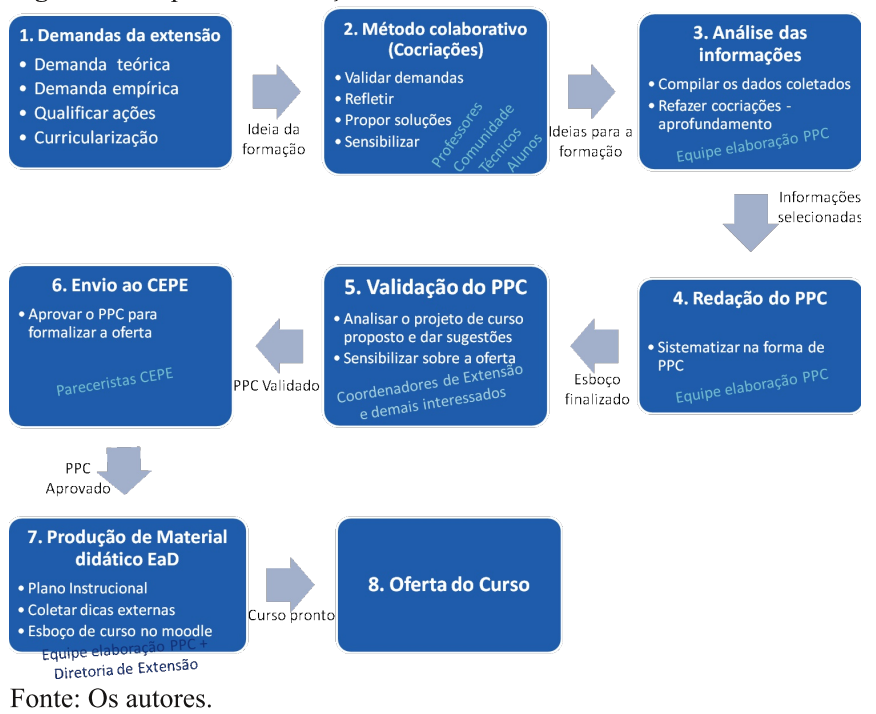

A despeito da aparente linearidade das etapas expostas na Figura 1, o desenvolvimento deste trabalho foi conduzido por meio de uma continua interação no desenvolvimento das referidas etapas entre a equipe de elaboração do PPC e os beneficiários, considerando as expectativas e aspirações de todos os atores envolvidos. Neste contexto, educadores (professores, técnicos, dirigentes) interagiram com alunos e comunidade, buscando estruturar um curso alinhado às necessidades formativas e interesses dos discentes.

\section{Resultados e Discussão}

Para a produção de um PPC adequado às realidades e necessidades institucionais, foram realizados três grupos focais com os públicos estratégicos relacionados ao objetivo da pesquisa. A Figura 2, a seguir, representa um desses momentos nos quais a pergunta central da pesquisa "Como operacionalizar a oferta deste curso no formado $\mathrm{EaD}$ em rede para todo o IFSC?" norteava o debate do grupo envolvido.

Figura 2 - Momento de interação durante a cocriação (grupo focal).

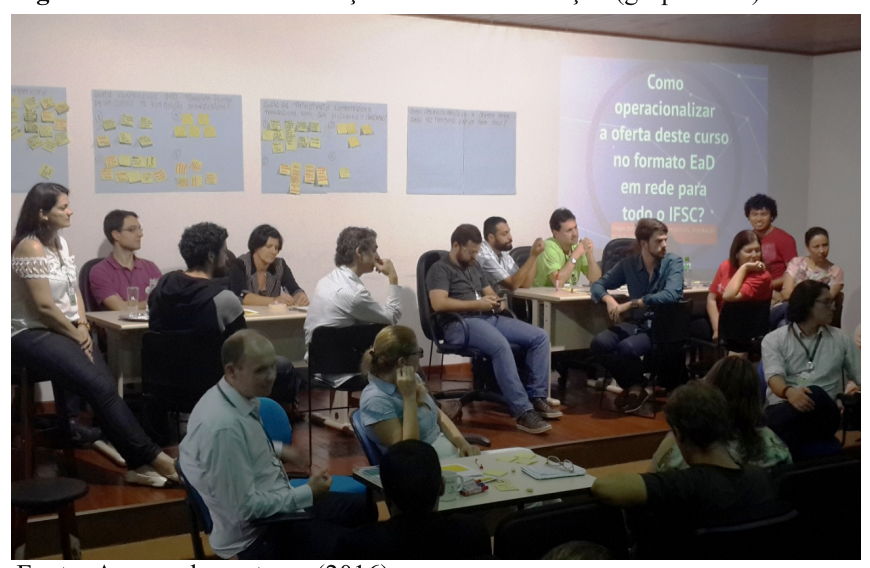

Fonte: Acervo dos autores (2016).

A partir da pergunta central, desmembram-se outras, as quais serviram como base para coleta de dados dos três encontros de cocriação, a saber:

- Quais as dificuldades da prática extensionista?

- Quais conteúdos não poderiam faltar em um curso de formação de extensionistas?

- Quais estratégias pedagógicas para formar extensionistas?

- Como operacionalizar oferta deste curso no formato $\mathrm{EaD}$ em rede para todo o IFSC?

As respostas para cada pergunta eram organizadas de modo a facilitar a visualização e interação. A Figura 3 ilustra esse processo: primeiramente, os participantes eram divididos em grupos de até cinco integrantes; depois, discutiam cada pergunta com tempo predefinido (10 minutos); em seguida, anotavam as proposições em post-its e as compartilhavam com todos (5 minutos); por fim, colavam nas cartolinas das respectivas perguntas. Depois, os participantes trocavam de grupo para debater com outros colegas a mesma questão.

Tais procedimentos foram realizados para todas as perguntas e tomaram cerca de 1 hora e 30 minutos. $\mathrm{O}$ roteiro proposto foi mediado pela equipe de elaboração do PPC e buscou estimular agilidade na geração de ideias acerca da temática.

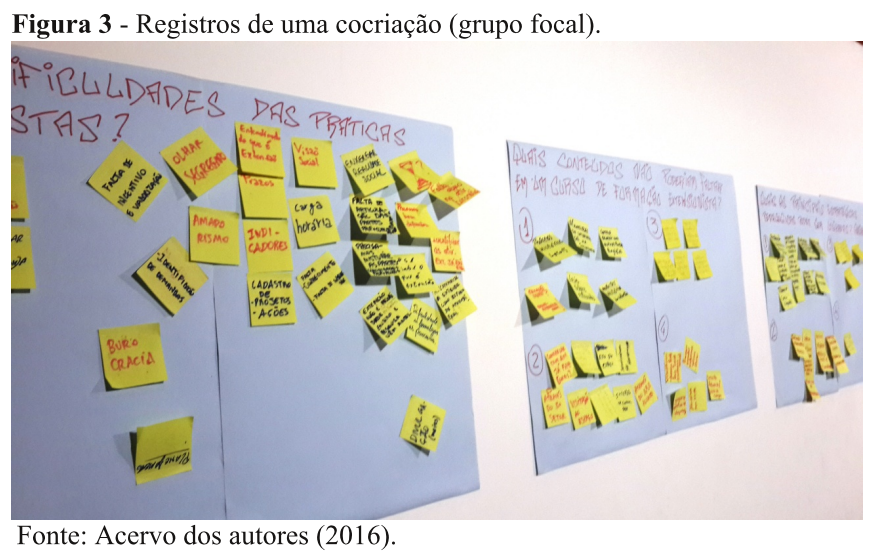

O ambiente descontraído e dinâmico estimulou os sujeitos, os quais demonstraram muito entusiasmo ao 
participarem ativamente das discussões. Como resultado das quatro perguntas norteadoras dos encontros de cocriação, foram obtidas informações que, após serem compiladas, foram devidamente consideradas no momento da escrita do projeto pedagógico do curso. O Quadro 1, a seguir, apresenta um exemplo de como as respostas foram compiladas e organizadas a partir da dinâmica apresentada na Figura 3.

Quadro 1 - Exemplo das respostas compiladas após o encontro de cocriação 02 .

\begin{tabular}{|c|c|}
\hline Perguntas & Respostas compiladas \\
\hline \multirow{25}{*}{$\begin{array}{l}\text { Quais as dificuldades na } \\
\text { prática extensionista? }\end{array}$} & $\begin{array}{l}\text { Não se sabe o que é extensão / Desconhecimento do que é } \\
\text { realmente extensão / Definir o que é realmente extensão / } \\
\text { Compreender o que é extensão / Entendimento do que é extensão } \\
\text { / Falta de conhecimento/consciência/interesse }\end{array}$ \\
\hline & $\begin{array}{l}\text { Extensão não é prioridade no imaginário do professor. Ensino e } \\
\text { pesquisa vêm antes }\end{array}$ \\
\hline & Despertar a causa da extensão \\
\hline & Reconhecer a extensão como espaço de aprendizado \\
\hline & $\begin{array}{l}\text { Grande quantidade de servidores novos e que desconhecessem a } \\
\text { forma de trabalhar }\end{array}$ \\
\hline & Falta de incentivo e valorização \\
\hline & Campus novo e implantação com equipes pequenas \\
\hline & $\begin{array}{l}\text { Olhar para fora / Enxergar realidade social / Verificar a demanda } \\
\text { / Compreender a dinâmica da região / Identificação de demandas } \\
\text { / Conhecimento dos arranjos produtivos locais por parte dos } \\
\text { servidores / Identificar as atividades de extensão já existentes }\end{array}$ \\
\hline & Olhar segregado \\
\hline & Visão social \\
\hline & $\begin{array}{l}\text { Falta de articulação das partes professor+comunidade+aluno / } \\
\text { Precisamos misturar as partes professor+comunidade+aluno }\end{array}$ \\
\hline & Falta de autonomia dos campi \\
\hline & Falta de apoio na atividade burocrática \\
\hline & $\begin{array}{l}\text { Burocracia excessiva / Burocracia da má vontade / Formulários } \\
\text { do Sigproj muito extenso }\end{array}$ \\
\hline & Dificuldade em formalizar as parcerias \\
\hline & Prazos \\
\hline & Divulgação \\
\hline & Amadorismo \\
\hline & Indicadores \\
\hline & Planejamento \\
\hline & \begin{tabular}{|l|} 
Fluxo lento \\
\end{tabular} \\
\hline & Agilidade (ausência) \\
\hline & Carga horária \\
\hline & Cadastro de projetos, ações \\
\hline & Processos bem definidos \\
\hline \multirow{8}{*}{$\begin{array}{l}\text { Como operacionalizar a } \\
\text { oferta deste curso em } \\
\text { formato EAD em rede? }\end{array}$} & Identificar demanda por campus com coordenador de extensão \\
\hline & Montar estrutura semelhante ao Pronatec \\
\hline & Definir atores tutor coord. Ofertar bolsas \\
\hline & Prever bolsas para tutores \\
\hline & Multiplicadores: coordenador de extensão e extensionista \\
\hline & Estrutura: capacitar os multiplicadores regionais (presencial) \\
\hline & $\begin{array}{l}\text { Formação de um grupo multidisciplinar para dar apoio à relação } \\
\text { do curso e articular criação do núcleo de extensão (coordenação, } \\
\text { bolsa, certificado para o curso e para o projeto) }\end{array}$ \\
\hline & $\begin{array}{l}\text { Edital de criação / fortalecimento de núcleos de extensão e redes } \\
\text { de extensão }\end{array}$ \\
\hline \multirow{25}{*}{$\begin{array}{l}\text { Quais as principais } \\
\text { estratégias pedagógicas } \\
\text { podem ser utilizadas? }\end{array}$} & Respostas similares - grupo 01 \\
\hline & \begin{tabular}{|l|} 
Semipresencial, visitas técnicas, saídas de campo \\
\end{tabular} \\
\hline & $\begin{array}{l}\text { Utilização de diferentes linguagens e suportes que alimentam o } \\
\text { Moodle vindo dos polos por encaminhamento dos alunos. } \\
\text { Sugestão: jogos }\end{array}$ \\
\hline & $\begin{array}{l}\begin{array}{l}\text { Aspectos sociais regionais e locais oriundos: história, geografia, } \\
\text { ciências sociais. }\end{array} \\
\end{array}$ \\
\hline & Vídeo do curso (suporte) \\
\hline & Material pensado para os diferentes públicos (libras) \\
\hline & As atividades realizadas consideradas para avaliação \\
\hline & Atividades em áudio \\
\hline & Levantamento de casos de extensão pelo aluno \\
\hline & Vídeos/conteúdos vindos dos polos encaminhados por alunos \\
\hline & Respostas similares - grupo 02 \\
\hline & Avaliação observatória \\
\hline & Fórum, vídeos \\
\hline & Ensino híbrido, espaço EAD para comunidade \\
\hline & Pesquisa da realidade local, pesquisa exploratória \\
\hline & Estratégias teóricas para diagnóstico. Ex: estudo de caso \\
\hline & Famílias de aprendizado \\
\hline & $\begin{array}{l}\text { Textos com conceitos básicos e exemplos. Valorizar imagens e } \\
\text { tornar o material mais lúdico possível }\end{array}$ \\
\hline & Realização de seminários \\
\hline & Casos de sucesso \\
\hline & Elaboração de projetos de extensão/ boas práticas/ seminários \\
\hline & Respostas similares - grupo 03 \\
\hline & Materializar (realização evento/oficina) \\
\hline & Avaliar criticamente a atividade \\
\hline & Compartilhar via vídeo conferência \\
\hline
\end{tabular}

\begin{tabular}{|l|l|}
\hline \multirow{4}{*}{} & Respostas similares - grupo 01 \\
\hline Educação: o que é? Ensino aprendizagem \\
\hline Maneiras de intervenção na sociedade \\
\hline Aspectos históricos locais \\
\hline Aspectos históricos da extensão \\
\hline Leis sobre extensão \\
\hline Como ocorre em outros países/regiões \\
\hline Respostas similares - grupo 02 \\
\hline Conversar com quem já faz (ONGs) \\
\hline $\begin{array}{l}\text { Quais conteúdos não } \\
\text { poderiam faltar em um } \\
\text { curso de formação } \\
\text { extensionista? }\end{array}$ & Divulgar mais o IFSC para a comunidade \\
\hline Uso do espaço \\
\hline Atividade em rede \\
\hline Inserido na comunidade \\
\hline Visitação as espaço \\
\hline Participação nos eventos locais \\
\hline Através do terceiro setor \\
\hline Sentimento de pertença \\
\hline Através do ser aluno \\
\hline Respostas similares - grupo 03 \\
\hline Metodologia de elaboração do projeto de extensão \\
\hline Metodologia de avaliação do projeto de extensão \\
\hline $\begin{array}{l}\text { Metodologia de sistematização do projeto (relacionar com o } \\
\text { formulário) }\end{array}$ \\
\hline $\begin{array}{l}\text { Mapeamento e diagnóstico de competências internas. Linhas e } \\
\text { núcleos de extensão }\end{array}$ \\
\hline $\begin{array}{l}\text { Indicar etapas de elaboração do projeto. "O projeto começa antes } \\
\text { do projeto" }\end{array}$ \\
\hline Respostas similares - grupo 04 \\
\hline Formulação de um projeto de extensão \\
\hline Promover eventos externos (oficina, show) \\
\hline Visualizar: arranjo produtivo local, dinâmica social \\
\hline Visita técnica/saída de campo \\
\hline
\end{tabular}

Fonte: Os autores.

Após analisar, selecionar e agrupar os dados coletados, foi possível utilizá-los para a elaboração do PPC. Os participantes sugeriram uma proposta do curso que articula teoria e prática em educação para extensão, a fim de proporcionar aos participantes, sinteticamente: 1) entendimento e sensibilização acerca da extensão; 2) contato e análise com o ambiente externo; e 3) a elaboração de uma proposta inicial de ação extensionista no espaço local.

A partir da análise dos resultados gerados, considerou-se relevante também inserir no curso conteúdos relacionados ao desenvolvimento da inovação social por meio de práticas extensionistas. Isso porque está no cerne da missão dos Institutos Federais e Universidades o propósito de contribuir para o desenvolvimento de soluções inovadoras para os problemas e desafios da sociedade. Considerando a definição de Juliani (2015), na qual a inovação social visa o redirecionamento de ações e projetos que equilibrem a geração de desenvolvimento econômico (lucro) e as questões socioambientais (sustentabilidade, responsabilidade social etc.), o curso buscou então focar também no desenvolvimento de projetos que estimulem esta visão nas atividades de ensino, pesquisa e extensão.

Partindo de todo o exposto, as competências gerais do egresso foram assim definidas:

- Compreender os aspectos teóricos da extensão para gerar, qualificar e dar visibilidade às práticas extensionistas desenvolvidas pela comunidade acadêmica do IFSC;

- Possibilitar a percepção das necessidades do ambiente externo e instrumentalizar a comunidade acadêmica para vincular essas necessidades aos processos de ensino, pesquisa e extensão;

- A partir do diagnóstico da realidade local, identificar demandas sociais e oportunidades de negócios e propor ações que explorem os conhecimentos 
adquiridos no curso, praticando a indissociabilidade entre pesquisa, ensino e extensão;

- Ampliar o senso de cidadania na comunidade acadêmica e a valorização do trabalho multidisciplinar, com foco na aproximação com a comunidade externa.

Figura 4 - Módulos do curso proposto.

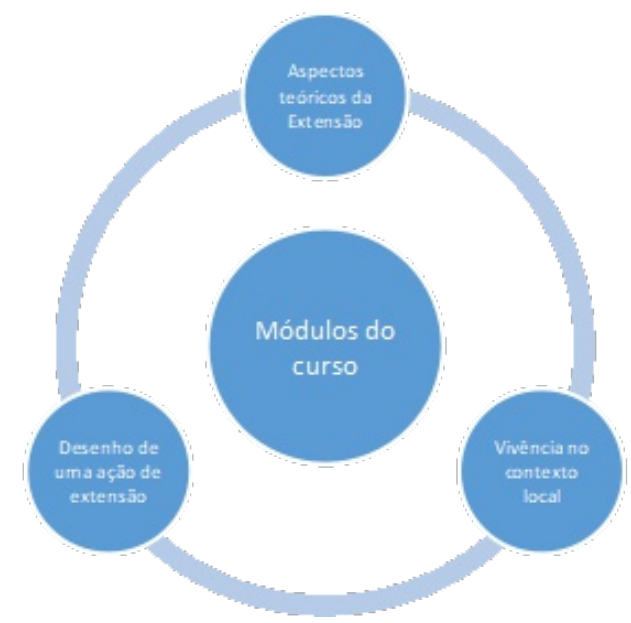

Fonte: Os autores.

No primeiro módulo, propõe-se a utilização de objetos de aprendizagem diversos, entre os quais se podem destacar as videoaulas, para estimular reflexões acerca dos aspectos conceituais da extensão, e videodepoimentos de membros de atividades de extensão/inovação social, com o intuito de apresentar a importância das ações extensionistas na formação do aluno e seu impacto na sociedade.

Para segundo módulo, preconizam-se conteúdos que suportem a realização e pesquisas de campo com a finalidade de identificar as necessidades locais. Os alunos deverão selecionar espaços para realizar visitas técnicas no entorno do câmpus. A visita será de caráter exploratório, acompanhada por um servidor do câmpus, e terá como finalidade promover a interação com a comunidade externa, oferecendo uma oportunidade de correlação explícita entre teoria e prática. Por exemplo, um grupo de alunos poderá realizar uma visita de campo a uma empresa para observar/mapear práticas de responsabilidade social aplicadas no cotidiano. Outra possibilidade seria visitar institutos de pesquisa, incubadoras, ONGs, start ups, movimentos sociais, centros de referência em assistência social e outras organizações que contribuam de alguma forma para a geração e implementação de soluções mais eficientes, justas e sustentáveis para as demandas de interesse público (sociais, ambientais ou econômicas), cujos valores criados atingem principalmente as perspectivas coletivas contrapostas às puramente individuais.

As visitas devem ser norteadas por um roteiro, o qual conterá um conjunto de componentes de planejamento, tais como objetivo, pauta, parceiros, critérios de análise de campo, entre outros, que auxiliarão o processo de observação e interação com a organização selecionada.

O terceiro módulo objetiva a geração e o desenho de soluções para as demandas identificadas. Os alunos (servidores e alunos regulares) deverão elaborar um vídeo de até 5 minutos que apresente uma proposta de ação extensionista, a qual, preferencialmente, esteja associada à sua área de interesse no curso em que está matriculado.

A estratégia pedagógica adotada visa facilitar o registro da proposta de ação extensionista de modo simples, prazeroso e significativo para o aluno. Foi pensada como uma ação preparatória a ser explorada por outros meios educacionais no câmpus/curso ao qual o aluno está vinculado, tal como para ser aprofundada e desenvolvida no projeto integrador ou trabalho de conclusão de curso.

O curso proposto, conforme já descrito, foi previsto para ser ofertado na modalidade a distância, ou seja, caracteriza-se por professores e estudantes que, na maior parte do tempo, encontram-se em locais distintos, interagindo em tempos diversos, por meio de tecnologias de informação e comunicação. Embora cursos a distância possam prever momentos presenciais, neste caso optou-se, pelas razões já mencionadas (autonomia e flexibilidade), por oferecer um curso de formação continuada totalmente online, somente com alguns encontros síncronos (com professores e estudantes interagindo ao mesmo tempo) ao longo do processo de ensino e aprendizagem. Esses encontros, realizados por meio de videoconferências e webconferências, são utilizados para comunicação com os participantes, principalmente nos casos que exigem maior interação entre os envolvidos, como quando se faz necessário explicar detalhadamente um tema / atividade ou socializar resultados de atividades propostas.

Dentre as atividades previstas para a conclusão com êxito do curso, os discentes devem realizar uma visita técnica orientada pela coordenação de extensão do campus ao qual estão vinculados. Essa ação exige uma articulação com a estrutura organizacional de extensão nos campi do IFSC, integrando, neste momento, portanto, o curso e os conhecimentos nele adquiridos à realidade institucional local na qual o discente está inserido.

Além disso, a interação, a mediação e a aprendizagem colaborativa acontecem durante todo o curso por meio de um Ambiente Virtual de Ensino e Aprendizagem (AVEA) institucional, que utiliza a plataforma gratuita Moodle. Nesse ambiente, a interação ocorre por meio de dispositivos que permitem a comunicação tanto de forma síncrona quanto assíncrona, possibilitando a criação de diferentes situações e procedimentos didáticos para incentivar a dialogicidade e a interação entre os atores envolvidos nesse processo. São explorados diversos objetos de aprendizagem, tais como livros e vídeos didáticos, wikis, fóruns e bases de dados, sempre visando diversificar as estratégias pedagógicas para facilitar o processo formativo dos diversos perfis de alunos.

$\mathrm{O}$ ambiente virtual estrutura-se e organiza-se de modo a refletir toda a estrutura pensada no PPC do curso. Os três módulos são organizados em tópicos que ganharam layouts criativos e atrativos para os participantes. A Figura 5, a seguir, apresenta a tela inicial do curso, composta por um banner de apresentação com o nome da formação, espaços para interação de docentes e discentes (Fórum de notícias e Fórum de Dúvidas) e, na sequência, vídeos e orientações sobre como se dá o desenvolvimento do curso. 
Figura 5 - Página inicial do curso no ambiente virtual de ensino e aprendizagem.
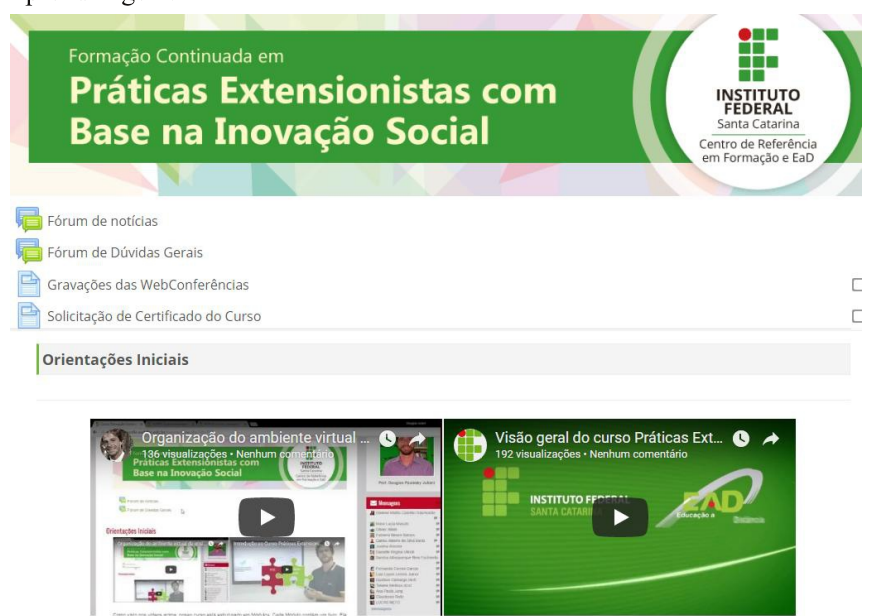
que você deve usar como gula para acessar todo o conteúdo e atividades dessa formação. É necessário realizar os desafilos 1, 2 e 3 para a conclusăo dos estudos. Inicie conhecendo o Projeto Pedagógico e o Cronograma / Roteiro de estudos, eles Irăo orientá.lo go desta caminhada!

Fonte: Acervo dos autores (2017)

Além disso, como estratégia de engajamento e valorização dos conhecimentos relacionados à extensão, e considerando que recursos como webconferências e videoconferências possibilitam a participação, interação e integração entre pessoas geograficamente distantes, previu-se também a participação, em cada oferta de professores convidados, inclusive de universidades internacionais. A Figura 6 retrata o momento de interação entre os estudantes do curso e o palestrante convidado para a aula inaugural, prof. dr. Jorge Cunha, da Universidade do Minho, de Portugal.

Figura 6 - Captura de tela da webconferência inaugural do curso com a participação do professor Jorge Cunha, da Universidade do Minho, de Portugal.

srfead

\section{Exemplos de IS (I)}

$$
\begin{aligned}
& \text { - Problema identificado: altas taxas de abandono escolar } \\
& \begin{array}{l}
\text { Estas escolas resultam da combinaçäo de esforços de diferentes } \\
\text { atores locais com o intuito de trazer de volta para o sistema }
\end{array} \\
& \text { educativo aqueles o jovens que por qualquer motivo se tinharn } \\
& \begin{array}{l}
\text { O afastamento destes alunos leva a que não adquiram } \\
\text { necessarias para os empregos disponivicis hoje em dia. }
\end{array}
\end{aligned}
$$

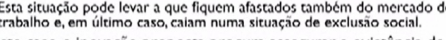

$$
\begin{aligned}
& \text { Nestc caso, a inovação proposta procura asscgurar a existência de }
\end{aligned}
$$

Fonte: Acervo dos autores (2017).

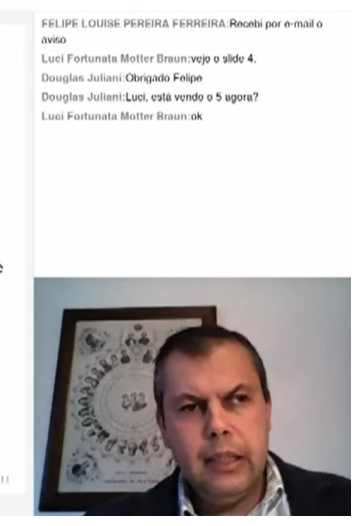

Toda a estrutura da proposta formativa, com seus objetivos, organização, metodologias e estratégias pedagógicas compuseram o PPC, pensado estrategicamente para atender, além do IFSC, à toda a rede dos Institutos Federais de Educação Profissional, Científica e Tecnológica.

Atualmente, o curso conta com uma carga horária de 90 horas e, conforme já citado, está composto por três grandes tópicos, a saber:

1. "Aspectos teóricos da Extensão e Inovação Social", que aborda tópicos introdutórios ao tema, tais como histórico, conceitos fundamentais, marcos legais e alguns exemplos práticos.
2. "Análise e vivência no contexto escolar", que tem como objetivo apresentar os métodos de pesquisa, as técnicas para observação e interação e como é possível realizar a elaboração de um relato com a identificação de demandas socioeconômicas locais.

3. "Desenho de uma ação" é o último tópico e, como tal, leva o participante para a elaboração do projeto de extensão propriamente dito.

O curso é oferecido conforme demanda institucional e prevê turmas de, no máximo, 30 alunos, sendo que o total de vagas possíveis em uma mesma oferta é de 150 . Não há pré-requisitos para a inscrição e é suficiente ter interesse no tema e participar do edital, no qual a forma de ingresso é realizada por meio de sorteio público. A bibliografia básica do curso adota, além de autores relacionados à metodologia de pesquisa (BRANCO NETO, 2013; CRESWELL, 2010; DEMO, 2005; etc.), artigo científicos relacionados aos temas da extensão e da inovação social (JULIANI, 2014; MURRAY; CAULIERGRICE; MULGAN, 2013; MULGAN, 2006; etc.).

A primeira oferta do curso aconteceu no segundo semestre de 2016, com 90 matriculados. Ao longo dos anos de 2017 e 2018 , as ofertas aconteceram semestralmente e atualmente totalizam um número de 340 participantes, sendo estes servidores professores e estudantes de institutos e universidades federais de todo o país. Avaliações periódicas do curso têm sido realizadas pelas equipes de docentes e pedagogos da instituição e também pelos discentes participantes. Estes dados têm sido compilados e irão compor publicações futuras.

\section{Conclusão/Considerações Finais}

Este artigo descreveu como foi construída uma proposta formativa na área de extensão, a qual foi concebida coletivamente a partir de fundamentos e técnicas do Design Thinking. Ela foi desenvolvida a partir da combinação de fontes de pesquisa diversas e da realização de cocriações com os públicos estratégicos, compreendendo alunos, servidores e comunidade externa. Entre os servidores, participaram membros da diretoria de extensão do IFSC (reitoria), coordenadores de extensão dos campi, professores internos e de instituições parceiras que possuem experiência em extensão. $\quad$ Foram realizados três encontros, utilizando-se técnicas de cocriação e os dados coletados foram sistematizados para a concepção do PPC proposto. Entende-se que essa metodologia contribuiu para uma concepção alicerçada em múltiplas visões de mundo, alinhada a demandas organizacionais e externas, bem como valorizou os anseios e necessidades da comunidade acadêmica em relação à prática da extensão.

Acredita-se que o método utilizado propiciou a construção centrada nas demandas do potencial aluno e de todos os outros envolvidos nessa formação. Trata-se de uma oferta articulada em conjunto com a PróReitoria de Extensão e Relações Externas para a qualificação das práticas extensionistas. Assim, a partir de uma proposta formativa crítica sobre extensão que articula o ensino, a pesquisa e as competências da 
comunidade acadêmica com demandas sociais (comunidade e empresas), espera-se o desenvolvimento de novas habilidades que fomentem ideias inovadoras e de impacto positivo no desenvolvimento local e regional onde esses discentes e servidores estão inseridos.

O curso, ofertado para alunos regulares e servidores de todas as áreas, constitui-se como uma proposta inovadora, na qual todos serão alunos e podem construir conhecimentos juntos ao longo das estratégias pedagógicas propostas. Oportuniza-se, assim, a aproximação / fortalecimento da relação alunoservidor e formação de grupos de pesquisa e extensão. $\mathrm{O}$ curso, por ser oferecido na modalidade a distância, apresenta-se disponível para todos os campi, o que abre a possibilidade de validar sua carga horária ou parte dela como atividade de extensão dos cursos regulares.

Por fim, espera-se que, ao passo que a formação é oferecida para toda a rede federal de educação, ela possa contribuir, em âmbito nacional, para: (1) o atendimento da carga horária mínima de extensão nos cursos dos institutos e universidades federais conforme o PNE vigente; (2) para enriquecer a formação e a geração de conhecimentos no campo da extensão; (3) para qualificar as atividades institucionais nesta área; e, principalmente, de modo a permitir ao discente participante a aplicação do conhecimento adquirido junto ao ambiente externo na comunidade, em empresas e outras organizações integrando e aplicando a indissociabilidade da tríade: ensino, pesquisa e extensão.

\section{Referências}

BLEICHER, S. Processos flexíveis para a produção de materiais didáticos para a educação a distância: recomendações pautadas na perspectiva interdisciplinar. 2015. 384 p. Tese (Doutorado) - Universidade Federal de Santa Catarina, Centro Tecnológico, Programa de PósGraduação em Engenharia e Gestão do Conhecimento, Florianópolis, 2015. Disponível em:

$<$ http://www.bu.ufsc.br/teses/PEGC0399-T.pdf>. Acesso em: 20 fev. 2018.

BRANCO NETO, W. C. Elaboração de Projetos de Pesquisa e Extensão. Apostila do curso de Elaboração de projetos de pesquisa e extensão. Lages 2013.

BRASIL. Congresso Nacional. Lei no 13.005, de junho de 2014. Aprova o Plano Nacional de Educação - PNE e dá outras providências. Disponível em:

$<$ http://www.planalto.gov.br/CCIVIL_03/_Ato2011-

2014/2014/Lei/L13005.htm>. Acesso em: 17 abr. 2018.

CRESWELL, J. W. Projeto de Pesquisa: métodos qualitativo, quantitativo e misto. Trad. Magda Franca Lopes. 3. ed. Porto Alegre: Artmed, 2010.

DEMO, P. Pesquisa: princípio científico e educativo. São Paulo: Cortez, 2005.

FORPROEX, Fórum e Pró-Reitores de Extensão das Universidades Públicas Brasileiras. Política nacional de extensão universitária. Manaus, 2012. Disponível em: $<$ https://www.ufmg.br/proex/renex/documentos/2012-07-13Politica-Nacional-de-Extensao.pdf $>$. Acesso em: $28 \mathrm{fev}$. 2018.
IDEO. Design Kit. Disponível em: $<$ http://www.designkit.org >. Acesso em: 12 jan. 2018.

JULIANI, D. P. et al. Inovação social: perspectivas e desafios. Revista Espacios, v. 35, n. 5, 2014.

JULIANI, D. P. Framework da Cultura Organizacional nas Universidades para a Inovação Social. 2015. 213 p. Tese (Doutorado em Engenharia e Gestão do Conhecimento) - Universidade Federal de Santa Catarina, Centro Tecnológico, Florianópolis, 2015. Disponível em: http://btd.egc.ufsc.br/wp-content/uploads/2015/05/DouglasPaulesky-Juliani.pdf. Acesso em: 01 abr. 2018.

MULGAN, Geoff. The process of social innovation. Innovations, v. 1, n. 2, p. 145-162, 2006.

MURRAY, R.; CAULIER-GRICE, J.; MULGAN, G. The Open Book of Social Innovation. London, NESTA/The Young Foundation, 2010. Disponivel em: http://www.nesta.org.uk/publications/open-book-socialinnovation. Acesso em: 12 dez. 2013.

VIANNA, M.; VIANN A, Y.; ADLER, I.; LUCENA, B.; RUSS O, B. Design Thinking. Inovação em negócios. 1 . ed. Rio de Janeiro: MJV Press, 2011. 